\title{
Rendimento de grãos de aveia branca (Avena sativa 1. .) em densidades de plantas e doses de nitrogênio ${ }^{1}$
}

\author{
White oat (Avena sativa l.) grains yield using different plant densities \\ and nitrogen levels
}

\section{Gessi Ceccon $^{2}$ Hélio Grassi Filho ${ }^{3}$ Sílvio José Bicudo ${ }^{4}$}

\section{RESUMO}

$O$ experimento foi realizado na Fazenda Experimental Lageado, Unesp Botucatu - SP, em um Nitossolo Vermelho distroférrico, em plantio direto sobre resteva de milho. $O$ delineamento experimental foi em blocos ao acaso, com quatro repetições. As densidades de plantas (60, 120, 180, 240 e 300 plantas $\mathrm{m}^{2}$ ) constituíram as parcelas e as doses de $\mathrm{N}$ em cobertura $\left(0,20,40,60\right.$ e $\left.80 \mathrm{~kg} \mathrm{ha}^{-1}\right)$ constituíram as sub-parcelas. O objetivo do trabalho foi avaliar o rendimento de grãos de aveia branca cultivada em diferentes densidades de plantas e doses de N. Os resultados foram submetidos à análise de variância (teste $F$ ), e as médias submetidas à regressão polinomial. Verificou-se interação significativa para as variáveis avaliadas. O rendimento de grãos foi influenciado positivamente pelas densidades e doses de N. O número final de panículas foi influenciado pelas médias de densidades de plantas e doses de $\mathrm{N}$ e o número de grãos por panícula foi influenciado negativamente pelas densidades $e$ positivamente pelas doses de N. A massa de mil grãos foi maior nas maiores densidades de plantas e nas doses intermediárias de N. Com redução na densidade inicial de plantas, o rendimento de grãos esperado foi alcançado com aumento na dose de $\mathrm{N}$ em cobertura. Com densidade normal de plantas e doses recomendadas de $\mathrm{N}$ em cobertura, o rendimento de grãos obtido foi maior que o esperado.

Palavras-chave: adubação, aveia, cereal de inverno, práticas de manejo.

\section{ABSTRACT}

This work had the aim to evaluate white oat grain yield as influenced by different plant densities and nitrogen levels. The experiment was carried out in the Lageado experimental farm at UNESP in the county of Botucatu in São Paulo state, Brazil. White oat was sown directly over corn residues in a Rhodic kanhapludalf soil. The experimental design was a split plot with four randomized blocks. Plant densities were allocated in plots and nitrogen levels in subplots. The results showed significant interaction between plant densities and nitrogen levels. Grain yield was positively influenced by plant densities and nitrogen level. The final number of panicle was negatively influenced by plant densities and was positively influenced by nitrogen levels. The weight of one thousand grains was greater at higher plant densities and at moderate nitrogen levels. With reduction in the initial density of plants, the expected yield grain was obtained with increase in the level of nitrogen in cover. In the normal density of plants and recommended levels of $N$ in covering, the obtained yield of grains was larger than the expected.

Key words: fertilization, oat, winter cereal, handling practices.

\section{INTRODUÇÃO}

A aveia branca (Avena sativa L.) é um cereal que apresenta múltiplos propósitos. Essa espécie é utilizada na alimentação humana, pelo teor de proteínas de qualidade e fibras solúveis, e na alimentação animal, como forragem verde, feno, silagem e na composição da ração. No sul do Brasil e em partes do Sudeste e Centro Oeste, é cultivada como espécie produtora de grãos e palha para a cobertura do solo, favorecendo a implantação das culturas de verão, especialmente em plantio direto.

\footnotetext{
${ }^{1}$ Parte da dissertação apresentada pelo primeiro autor ao Programa de Pós-graduação em Agricultura, Faculdade de Ciências Agronômicas (FCA), Universidade Estadual Paulista (UNESP).

${ }^{2}$ Engenheiro Agrônomo Doutor, Embrapa Agropecuária Oeste. BR 163, km 253, CP 661, 79804-970, Dourados, MS. E-mail: ceccon@cpao.embrapa.br. Autor para correspondência.

${ }^{3}$ Professor Adjunto, Doutor, Departamento de Recursos Naturais, UNESP Botucatu - SP

${ }^{4}$ Professor Titular, Doutor, Departamento de Produção Vegetal, UNESP Botucatu - SP
} 
A densidade de semeadura recomendada para a aveia é de 200 a 300 sementes aptas $\mathrm{m}^{2}$, com espaçamento de 0,17 a $0,20 \mathrm{~m}$ entre linhas (FERREIRA FILHO et al., 1998). As adubações são realizadas com base na análise química do solo (COMISSÃO..., 2000) e também no rendimento esperado (RAIJ et al., 1997). A adubação nitrogenada em cobertura é recomendada, em condições favoráveis de clima e solo, aos 30 dias após a emergência das plantas (COMISSÃO..., 2000).

A expressão de potenciais de rendimento da aveia está associada às técnicas de manejo, entre elas, a população de plantas e a disponibilidade de nutrientes, como o nitrogênio $(\mathrm{N})$, que é um importante nutriente para o crescimento dos tecidos e constituição de proteínas. O nitrogênio que compõe a proteína dos grãos pode ser relacionado com o conteúdo de $\mathrm{N}$ na planta no início da floração (BROUWER \& FLOOD, 1995).

Avaliando o efeito de densidades de plantas e doses de nitrogênio, em Iowa (EUA), FREY (1959) encontrou aumentos de rendimento de grãos de 50 a $60 \%$ com a aplicação de N, devido ao maior número de panículas e de grãos por panícula. Na Austrália, SOUTHWOOD et al. (1974) constataram que 22,4kg $\mathrm{ha}^{-1}$ de nitrogênio foi a melhor dose para o rendimento de grãos, mas a resposta às doses de $\mathrm{N}$ não foi influenciada pelas densidades de semeadura. BRINKMAN \& RHO (1984), em Wisconsin (EUA), verificaram que o efeito das doses de $\mathrm{N}$ sobre a densidade de semeadura pode ser descrito por uma função quadrática, independente do cultivar utilizado. Na Polônia, KROL et al. (1986), avaliando densidades de 550 e 650 plantas $\mathrm{m}^{2}$, espaçadas de 0,065 e $0,13 \mathrm{~m}$, com doses de 0 a $120 \mathrm{~kg} \mathrm{ha}^{-1}$ de nitrogênio, observaram maior rendimento de grãos nas maiores densidades e menor espaçamento, independente da dose de $\mathrm{N}$, e constataram que as doses econômicas de $\mathrm{N}$ estavam entre 30 e $90 \mathrm{~kg} \mathrm{ha}^{-1}$. Na Pensylvania, MARSHALL et al. (1987), avaliando densidades de plantas e doses de nitrogênio, encontraram interação significativa descrita com equações linear e quadrática, para o efeito de desses dois fatores sobre o rendimento de grãos. Segundo esses autores, há maior rendimento nas maiores densidades e nas doses intermediárias de $\mathrm{N}$. Na República Checa, ULMANN (1992) obteve rendimento médio de grãos de $3.290 \mathrm{~kg} \mathrm{ha}^{-1}$, avaliando densidades de 450 e 550 plantas $\mathrm{m}^{2}$, com doses de 60 e $90 \mathrm{~kg} \mathrm{ha}^{-1}$ de $\mathrm{N}$, e encontrou melhores resultados nas maiores densidades e maiores doses de $\mathrm{N}$, com rendimento de grãos de $6.140 \mathrm{~kg} \mathrm{ha}^{-1}$. Na Finlândia, PELTONEN-SAINIO (1997), avaliando 400, 500, 600,700 e 800 sementes viáveis $\mathrm{m}^{2}$, encontrou maior número de panículas por planta nas menores densidades. MALHI et al. (2001) realizaram uma revisão sobre adubação nitrogenada em cereais em plantio direto no Canadá, na qual discorrem sobre vários fatores que interferem na absorção de nutrientes, destacando que a presença de palha em decomposição pode otimizar os processos de aproveitamento de nitrogênio pelas plantas.

No Brasil, DARTORA \& FLOSS (2002b), não encontraram interação significativa entre densidade de plantas e doses de $\mathrm{N}$ em cobertura no rendimento de grãos e estimaram maiores valores na densidade de 127plantas $\mathrm{m}^{2}$, independente do cultivar e da dose de $\mathrm{N}$ em cobertura, com equação linear inversamente proporcional às doses, com maior rendimento de grãos na dose $30 \mathrm{~kg} \mathrm{ha}^{-1}$. FONTOURA \& MORAES (2002) observaram efeito da densidade de semeadura, com maior rendimento de grãos nas densidades 200, 300 e 400 plantas $\mathrm{m}^{2}$.

Foi observado aumento linear do número final de panículas e redução do número de grãos por panícula, com o aumento da densidade de plantas e doses de N (DARTORA \& FLOSS, 2002a). Os autores observaram interação significativa para massa de mil grãos, porém com regressão significativa apenas para o cultivar UPF 16 na dose zero e para o cultivar UPF 19 na dose $30 \mathrm{~kg} \mathrm{ha}^{-1}$ de $\mathrm{N}$ em cobertura.

O presente trabalho foi desenvolvido com o objetivo de avaliar o rendimento de grãos e os componentes de rendimento de aveia branca em densidades de plantas e doses de $\mathrm{N}$ em cobertura.

\section{MATERIAL E MÉTODOS}

O trabalho foi desenvolvido na Fazenda Experimental Lageado, na Faculdade de Ciências Agronômicas da UNESP - Botucatu/SP, localizada nas coordenadas $22^{\circ} 49^{\prime}$ latitude sul, $48^{\circ} 24^{\prime}$ longitude oeste e altitude $770 \mathrm{~m}$, em Nitossolo Vermelho distroférrico textura muito argilosa (CARVALHO et al., 1983). O experimento foi implantado sobre palha de milho em linhas espaçadas de 0,20m, no dia 26/ 03/98, utilizando-se o cultivar UPF 17, com emergência plena no dia 06 de abril, e as densidades de plantas ajustadas entre os dias 13 e 20/04/98.

O solo foi amostrado segundo RAIJ et al. (1997) e analisado pela metodologia descrita por RAIJ \& QUAGGIO (1983) e apresentou $\mathrm{pH}_{(\mathrm{CaCl} 2)}=5,4 ; \mathrm{MO}$ $=29 \mathrm{~g} \mathrm{dm}^{-3} ; \mathrm{P}_{\text {(resina) }}=9 \mathrm{mg} \mathrm{dm}^{-3} ; \mathrm{K}=3,4 \mathrm{mmol}_{\mathrm{c}} \mathrm{dm}^{-3} ; \mathrm{Ca}$ $=37 \mathrm{mmol}_{\mathrm{c}} \mathrm{dm}^{-3} ; \mathrm{Mg}=16 \mathrm{mmol}_{\mathrm{c}} \mathrm{dm}^{-3}, \mathrm{CTC}=87 \mathrm{mmol}_{\mathrm{c}}$ $\mathrm{dm}^{-3}$ e $\mathrm{V}=64 \%$. A adubação na semeadura foi realizada segundo RAIJ et al. (1997) e constou de $30 \mathrm{~kg}$ $\mathrm{ha}^{-1}$ de nitrogênio na forma de uréia, $60 \mathrm{~kg} \mathrm{ha}^{-1} \mathrm{de}_{2} \mathrm{O}_{5}$ 
na forma de superfosfato triplo e superfosfato simples, $10 \mathrm{~kg} \mathrm{ha}^{-1}$ de $\mathrm{K}_{2} \mathrm{O}$ na forma de cloreto de potássio e $10 \mathrm{~kg} \mathrm{ha}^{-1}$ de enxofre na forma de superfosfato simples. Esses adubos foram misturados, homogeneizados e aplicados na semeadura. As doses de $\mathrm{N}$ (uréia) aplicadas em cobertura, aos 25 dias após a emergência, constituíram as subparcelas.

Durante o cultivo da aveia, foram registrados $309 \mathrm{~mm}$ de chuva, assim distribuídos: março $=81 \mathrm{~mm} ;$ abril $=64 \mathrm{~mm} ;$ maio $=134 \mathrm{~mm}$; junho $=13 \mathrm{~mm} ;$ julho $=15 \mathrm{~mm}$ e agosto $=56 \mathrm{~mm}$.

A colheita foi realizada durante a maturação plena, na primeira quinzena de agosto, colhendo-se as plantas de cinco linhas centrais de cada subparcela, e após secas ao sol e trilhadas, foi determinado o rendimento de grãos.

Os componentes de rendimento foram quantificados em uma linha de um metro de cada subparcela; o número final de panículas foi determinado pela contagem do número de panículas granadas; a massa de mil sementes foi obtida avaliando-se a massa de 500 grãos e o resultado multiplicado pelo índice 2; e o número de grãos por panícula (NGP) foi calculado pela fórmula: NGP = $1.000^{*}(\mathrm{MTS} / \mathrm{MMS}) /(\mathrm{NFP})$, onde: $\mathrm{MTS}=$ massa total de sementes de cada subparcela; $\mathrm{MMG}=$ massa de mil grãos; NFP = número final de panículas e $1.000=$ fator de correção.

O delineamento experimental foi em blocos ao acaso com parcelas subdivididas, com quatro repetições/tratamento. As parcelas principais foram constituídas pelas densidades $(60,120,180,240$ e 300 plantas $\mathrm{m}^{2}$ ) e as subparcelas pelas doses de $\mathrm{N}$ em cobertura (zero, 20, 40, 60, e 80 $\mathrm{kg} \mathrm{ha}^{-1} \mathrm{de} \mathrm{N}$ ), as quais foram estabelecidas para o rendimento esperado de $3.000 \mathrm{~kg} \mathrm{ha}^{-1}$ de grãos. As subparcelas foram constituídas de 13 linhas de 4m, com 0,2m entre linhas afastadas em $1 \mathrm{~m}$ entre elas. Os resultados foram submetidos à análise de variância (teste F) e regressão polinomial utilizando-se o programa estatístico SAS (SAS Institute, 1989). As médias são apresentadas em superfície de resposta (PIMENTEL GOMES, 1990), utilizando software Surfer versão Win 32 (SMITH et al, 1995) para representação gráfica dos valores transformados.

\section{RESULTADOS E DISCUSSÃO}

A massa de grãos e o número de grãos por panícula apresentaram significância a $1 \%$ de probabilidade de erro; o rendimento de grãos a $5 \%$ e o número final de panículas a $8 \%$ de probabilidade de erro (Tabela 1), melhor representados pela equação quadrática. $\mathrm{O}$ rendimento esperado de grãos (Figura 1A) foi alcançado a partir da densidade de 60 plantas por $\mathrm{m}^{2}$ com e a dose de $60 \mathrm{~kg} \mathrm{ha}^{-1}$ de $\mathrm{N}$ em cobertura e com a densidade 120 plantas por $\mathrm{m}^{2}$ sem $\mathrm{N}$ em cobertura. MARSHALL et al. (1987) encontraram resultados semelhantes, porém diferentes de FONTOURA \& MORAES (2002) e de DARTORA \& FLOSS (2002b) que, aplicando regressão polinomial, encontraram efeito simples de densidade de plantas e de doses de $\mathrm{N}$ em cobertura. Estes dois últimos trabalhos, realizados no sul do Brasil, utilizaram, respectivamente, 7 e $10 \mathrm{~kg} \mathrm{ha}^{-1}$ de $\mathrm{N}$ na semeadura, sendo o $\mathrm{N}$ em cobertura aplicado 30 dias após a emergência das plantas (COMISSÃO...2000), enquanto que, no presente trabalho, utilizou-se $30 \mathrm{~kg}$ $\mathrm{ha}^{-1}$ de $\mathrm{N}$ na semeadura, o que potencializou altos rendimentos, mesmo sem $\mathrm{N}$ em cobertura. Isso pode ser atribuído ao maior número final de panículas (Figura 2A), independente da dose de $\mathrm{N}$ em cobertura. Com isso, pode-se considerar que, em caso de redução da densidade inicial de plantas, a produtividade esperada pode ser alcançada com maior dose de $\mathrm{N}$ em cobertura, desde que seja aplicado o mais cedo possível e em condições de umidade e temperatura favoráveis. Com a população de plantas recomendada, o rendimento esperado pode ser superado com a adubação em cobertura.

Efeito quadrático das doses de $\mathrm{N}$ sobre a densidade normal de semeadura foi observado por BRIKMAN \& RHO (1984), enquanto DARTORA \& FLOSS (2002b) constataram que a equação linear

Tabela 1 - Probabilidade de significância indicado pelo teste $\mathrm{F}$ da análise de regressão, no experimento com aveia branca (Avena sativa L.) cv. UPF 17 sob densidades de plantas e doses de Nitrogênio em cobertura, em Botucatu, 2003.

\begin{tabular}{lccc}
\hline Variável & Densidade de plantas & Doses de nitrogênio $^{*}$ & Interação Densidade x Dose $^{*}$ \\
\hline Rendimento de grãos & 0,0043 & 0,0001 & 0,0326 \\
Massa de mil grãos & 0,0001 & 0,1145 & 0,0010 \\
Número final de panícula & 0,0001 & 0,0026 & 0,0816 \\
Número de grãos por panícula & 0,0001 & 0,0056 & 0,0034 \\
\hline
\end{tabular}

* Valores menores que 0,05 indicam efeito significativo em nível de $5 \%$ de probabilidade de erro. 


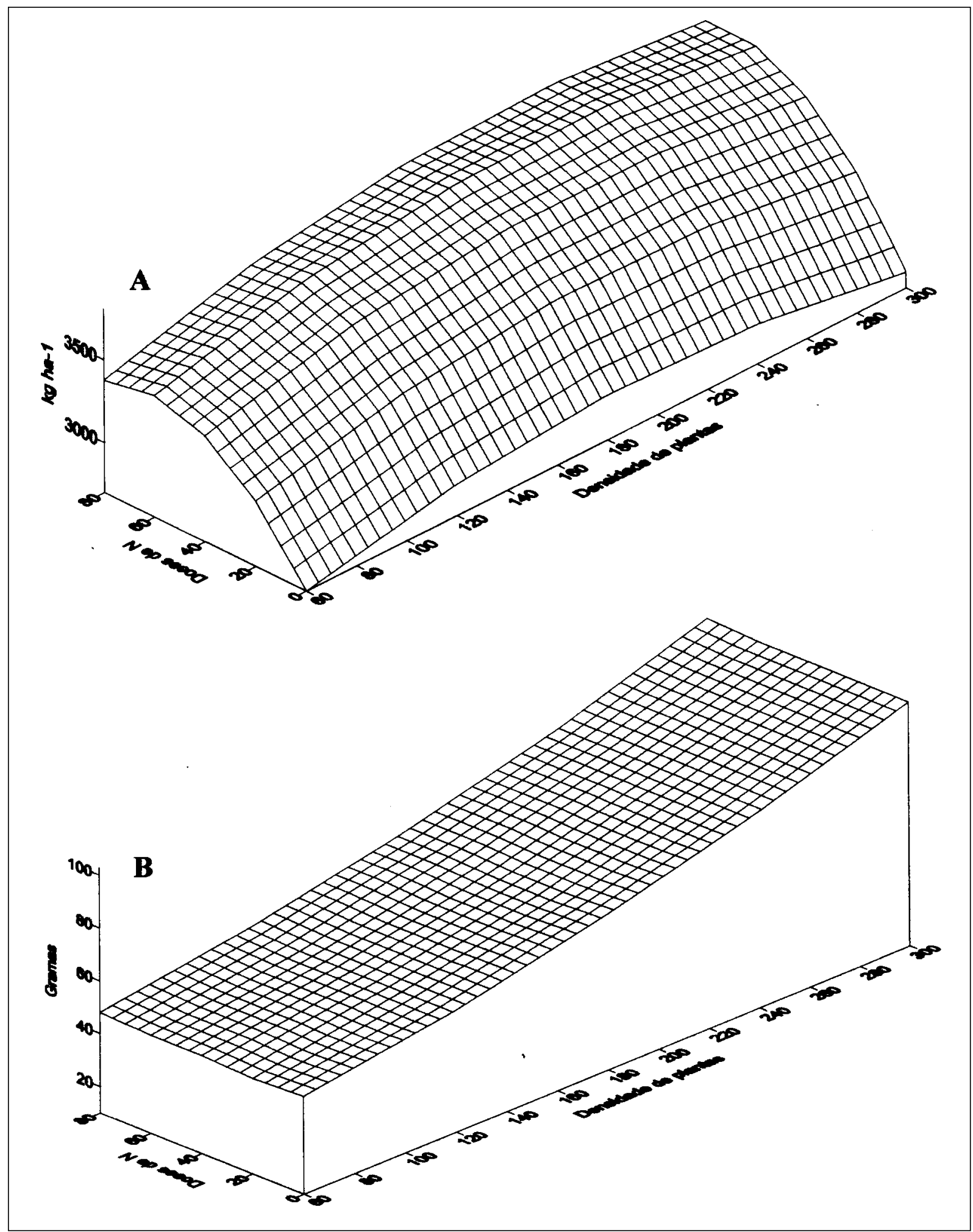

Figura 1 - Rendimento de grãos (A) em kg ha ${ }^{-1}$ e massa de mil grãos (B) em gramas, de aveia branca (Avena sativa $\mathrm{L}$.) cv. UPF 17 sob densidades de plantas e doses de N em cobertura, em Botucatu, 2003. Equação de $\left.\mathrm{A}: \mathrm{y}=2394+\left(5,978^{*} \mathrm{x}\right)+(22,87 * \mathrm{y})+\left(-0,01549 * \mathrm{x}^{2}\right)\right)+(-$ $\left.0,189 * y^{2}\right)+(1,271 * x y) ; R^{2}=0,89 ;$ Equação de B: $y=40,39+(0,0869 * x)+(-0,0098 * y)+\left(0,000405 * x^{2}\right)+\left(0,00031249 * y^{2}\right)+(-$ $\left.0,0000489^{*} \mathrm{xy}\right) ; \mathrm{R}^{2}=0,77$.

Ciência Rural, v.34, n.6, nov-dez, 2004. 


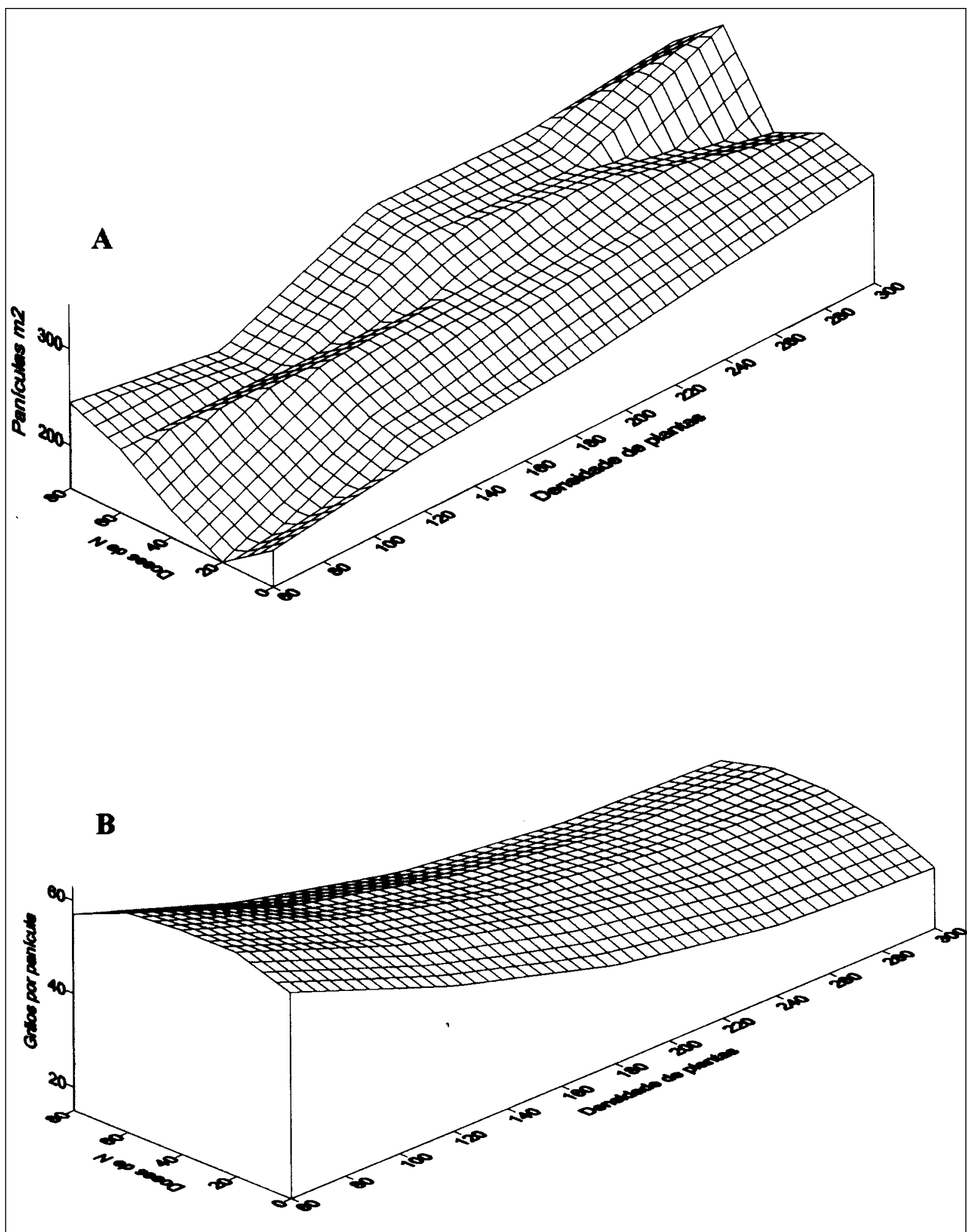

Figura 2 - Número final de panículas por $\mathrm{m}^{2}(\mathbf{A})$ e número de grãos por panícula (B) de aveia branca (Avena sativa $\mathrm{L}$.) cv. UPF $17 \mathrm{sob}$ densidades de plantas e doses de $\mathrm{N}$ em cobertura, Botucatu, 2003. Equação de $\mathrm{A}: \mathrm{y}=133,5+(0,754 * \mathrm{x})+(0,98 * \mathrm{y})+\left(-0,00101 * \mathrm{x}^{2}\right)+(-$ $\left.0,00258 * y^{2}\right)+(-0,0000489 * x j) ; R^{2}=0,69$. Equação de $B: y==76,02+(-0,309 * x)+(0,239 * y)+\left(0,000498 * x^{2}\right)+(-$ $\left.0,00354 * \mathrm{y}^{2}\right)+(0,00031 * x y) ; \mathrm{R}^{2}=0,88$.

Ciência Rural, v.34, n.6, nov-dez, 2004. 
descreveu melhor o efeito das doses de nitrogênio, independente da densidade de plantas. Houve resposta às doses de $\mathrm{N}$ em cobertura, porém, o rendimento esperado foi alcançado nas densidades recomendadas (180 e 240 plantas $\mathrm{m}^{2}$ ), sem aplicação de $\mathrm{N}$ em cobertura e, nas densidades de 60 e 120 plantas $\mathrm{m}^{2}$ (densidades inferiores à recomendada) com as doses 20 e $40 \mathrm{~kg} \mathrm{ha}^{-1}$ de $\mathrm{N}$ em cobertura, semelhante aos resultados encontrados por SOUTHWOOD et al. (1974) e por ULMANN (1992). FLOSS et al. (1996), avaliando doses de $\mathrm{N}$ em cobertura sobre resteva de milho, encontraram maior rendimento de grãos nas doses 40 e $60 \mathrm{~kg} \mathrm{ha}^{-1}$ de $\mathrm{N}$, porém sem diferir estatisticamente das doses 20 e $80 \mathrm{~kg} \mathrm{ha}^{-1}$.

Considerando o cultivo de aveia branca em condições de baixa disponibilidade hídrica, e altas taxas de perdas de $\mathrm{N}$ aplicado em cobertura, principalmente em condições de plantio direto, com palha na superfície (SENGIK \& KIEHL, 1995), a adubação na semeadura (30kg ha-1 de N), conforme foi realizado nesse trabalho, torna-se importante, e a aplicação em cobertura deve ser criteriosamente planejada, a fim de evitar perdas do nutriente por evaporação (SENGIK \& KIEHL, 1995 e MALHI et al., 2001). No entanto, havendo redução inicial do estande, o rendimento esperado pode ser alcançado com maiores doses de $\mathrm{N}$ em cobertura desde que em condições climáticas favoráveis à prática.

$\mathrm{O}$ número final de panículas apresentou maiores valores entre as doses 40 e $60 \mathrm{~kg} \mathrm{ha}^{-1} \mathrm{de} \mathrm{N}$ em cobertura, semelhante aos resultados encontrados por FREY (1959), e efeito significativo para médias de densidades de plantas conferindo com FONTOURA $\&$ MORAES (2002).

Nas menores densidades de plantas, observou-se maior número final de panículas (Figura 2A), comparativamente com as densidades iniciais, que favoreceu a manutenção de altos níveis de rendimento mesmo nas menores densidades de plantas. DARTORA \& FLOSS (2002a) verificaram aumento linear do número final de panículas $\mathrm{m}^{2}$, na média das doses de $\mathrm{N}$ em cobertura, com o aumento das densidades de plantas.

Os valores de número de grãos por panícula (Figura 2B) corroboram com os resultados de PELTONEN-SAINIO (1997), que encontrou maior produção de panículas por planta e maior número de grãos nas menores densidades de plantas. DARTORA \& FLOSS (2002a) verificaram redução do número de grãos por panícula com aumento das densidades e doses de N. No presente trabalho, as densidades de plantas interferiram no número de grãos por panícula, em todas as doses observadas, na razão inversamente proporcional (Figura 2B).
A massa de mil grãos foi influenciada de forma significativa pela interação entre densidades de plantas e doses de $\mathrm{N}$, apresentando um aumento nas maiores densidades (Figura 1B), semelhante aos resultados de BRINKMAN \& RHO (1984). FLOSS et al. (1996) encontraram maior massa de grãos, sem $\mathrm{N}$ aplicado em cobertura, a qual não diferiu da dose $20 \mathrm{~kg} \mathrm{ha}^{-1}$ de N em cobertura, logo, DARTORA \& FLOSS (2002a) verificaram interação significativa entre densidades de plantas, doses de $\mathrm{N}$ e cultivares, para a massa de mil grãos.

As menores densidades de plantas proporcionaram maior número de grãos por panícula, e menor massa de grãos, com relação inversa nas maiores densidades, semelhante aos resultados apresentados por BROUWER \& FLOOD (1995). Neste trabalho, o rendimento esperado foi alcançado com as menores doses de $\mathrm{N}$.

\section{CONCLUSÕES}

Com a redução na densidade inicial de plantas, o rendimento esperado foi alcançado com aumento na dose de $\mathrm{N}$ em cobertura. Com densidades normais de plantas, e doses recomendadas de $\mathrm{N}$ em cobertura, o rendimento de grãos obtido foi maior que o esperado.

\section{REFERÊNCIAS BIBLIOGRÁFICAS}

BRINKMAN, M.A.; RHO, Y.D. Response of three oat cultivars to N fertilizer. Crop Science, Madison, v.24, p.973977, 1984.

BROUWER, J.; FLOOD, R.G. Aspects of oat physiology. In: WELCH, R.W. The oat crop: production and utilization. London : Chapman e Hall, 1995. p.203-211.

CARVALHO, W.A. et al. Levantamento de solos da fazenda experimental Presidente Médici. Botucatu : FCA/UNESP, 1983. 95p. (Boletim Científico n.1).

COMISSÃO BRASILEIRA DE PESQUISA DE AVEIA. Recomendações técnicas para a cultura da aveia. Pelotas: Universidade Federal de Pelotas Evangraf, 2000. 69p.

DARTORA, K.S.; FLOSS, E.L. Componentes de rendimento de grãos em aveia branca sob diferentes doses de nitrogênio e densidades de plantas. In: REUNIÃO DA COMISSÃO BRASILEIRA DE PESQUISA DE AVEIA, 22., 2002, Passo Fundo. Resultados experimentais. Passo Fundo : EDUPF, 2002a. p.731.

DARTORA, K.S.; FLOSS, E.L. Rendimento de grãos em aveia branca sob diferentes doses de nitrogênio e densidades de plantas. In: REUNIÃO DA COMISSÃO BRASILEIRA DE PESQUISA DE AVEIA, 22., 2002, Passo Fundo. Resultados experimentais. Passo Fundo : EDUPF, 2002b. p.729. 
FERREIRA FILHO, A.W.P. et al. Aveia Avena sativa L. In: Instruções agrícolas para as principais culturas econômicas. 6.ed. Campinas : Instituto Agronômico. 1998. p.33. (Boletim 200).

FLOSS, E.L. et al. Doses de nitrogênio em cobertura em aveia sobre resteva de milho, 1995. In: REUNIÃO DA COMISSÃO SULBRASILEIRA DE PESQUISA DE AVEIA, 16., 1995, Passo Fundo. Resultados experimentais. Florianópolis : Universidade Federal de Santa Catarina, 1996. p.306-309.

FONTOURA, S.M.; MORAES, R.P. de. Efeito do nitrogênio em cobertura e da densidade de plantas no rendimento de grãos de aveia branca. REUNIÃO DA COMISSÃO BRASILEIRA DE PESQUISA DE AVEIA, 22., 2002, Passo Fundo. Resultados experimentais. Passo Fundo : EDUPF, 2002. p.719-720.

FREY, K.J. Yield components in oats. II. The effect of nitrogen fertilization. Agronomy Journal, Madison, v.51, n.10, p.605$608,1959$.

KROL, M. et al. Effect of nitrogen fertilization and sowing density on yield of oats cv. Markus on soils of the good rye complex. Pamietnik-Pulawski, Pulawy, Poland, n.87, p.125137, 1986.

MALHI, S.S. et al. Nitrogen fertilization management for no-till cereal production in the Canadian Great Plains: a review. Siol \& Tillage Research, Amsterdam, v.1, p.101-122, 2001.

MARSHALL, H.G. et al. Effects of nitrogen fertilizer rate, seeding rate, and row spacing on semidwarf and conventional height spring oat. Crop Science, Madison, v.27, p.572-576 1987.
PELTONEN-SAINIO, P. Groat yield and plant structure of naked and hulder oat under different nitrogen fertilizer and seeding rates. Agronomy Journal, Madison, v.89, n.1, p.140-147, 1997.

PIMENTEL GOMES, F. Estatística Experimental. 13.ed Piracicaba : Nobel, 1990. p.374-382

RAIJ, B. et al. Recomendações de adubação e calagem para o estado de São Paulo. 2.ed. Campinas : Instituto Agronômico, 1997. p.11-53. (Boletim técnico, 100).

RAIJ, B.V.; QUAGGIO, A.J. Métodos de análise de solo para fins de fertilidade. Campinas : Instituto Agronômico, 1983. 31p. (IAC - Boletim técnico, 81).

SAS Institute Inc. SAS/STAT user's guide, version 6.4. 4.ed. Cary, 1989. V.2, 846p

SENGIK, E.; KIEHL, J.C. Controle da volatilização da amônia em terra roxa tratada com uréia e turfa pelo emprego de sais inorgânicos. Revista Brasileira de Ciência do Solo, v. 19, p.449454, 1995.

SMITH, D. et al. Surface mapping system. Colorado, 1995.

SOUTHWOOD, O.R. et al. Response of oats to seeding rate and nitrogen in the southern wheat belt of New South Wales. Department of Agriculture, Agricultural Research Institute. Australian Journal of Experimental Agriculture and Animal Husbandry, Melbourne, v.14, n.67, p.231-236, 1974.

ULMANN, L. Grain yields of oats cv. Ardo at different rates of nitrogen fertilizers and sowing. Vyzkumny Ustav Obilnarsky, 767 41 Kromeriz, Czech Republic. Rostlinna-Vyroba, v.38, n.11, p.929-934, 1992 